\title{
Dimensional stability of reinforced bitumen sheets as a possible source of flat roof defects
}

\author{
Jan Plachý1, ${ }^{1}$, Jana Vysoká1, and Radek Vejmelka ${ }^{1}$ \\ ${ }^{1}$ The Institute of Technology and Business in České Budějovice, Okružní 10, 37001 České \\ Budějovice
}

\begin{abstract}
This paper follows up on the results of a research presented at the conference Building Defects 2017. The paper deals with the dimensional stability of bitumen sheets. The manifestation of insufficient dimensional stability is the shrinkage of bitumen sheets in the transverse joints. Shrinkage of bitumen sheets with reinforced polyester liner and a non-reinforced glass fiber is primarily due to insufficient technological discipline. The paper deals with the influence of melting of the sheet on its possible shrinkage during roof exposure. Previous research has shown that the shrinkage happening during melting accounts for more than $50 \%$ of the total shrinkage. The aim of this paper is to show the size of the effect on the biasing of the load-bearing insert during the realization of the waterproofing layer in bitumen sheets with a glass-reinforced polyester carrier liner. The experiment, expressed by the dimensional stability test according to ČSN EN 1107, was performed in a laboratory on three samples of bitumen sheets. Bitumen sheets had different types of reinforcement and a different weight of the carrier liner.
\end{abstract}

\section{Introduction}

The longitudinal shrinkage of bitumen sheets on flat roofs is one of the causes of failures of bitumen sheets [1], see Figure 1.

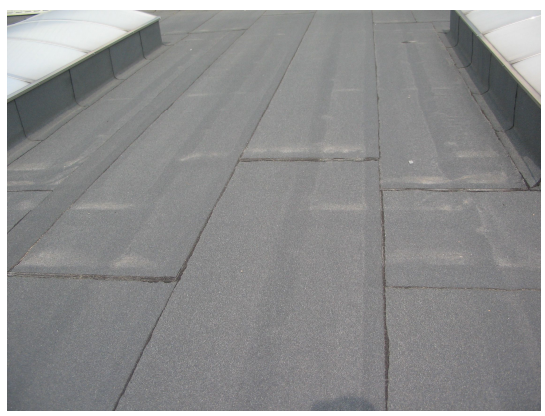

Fig. 1. Bitumen sheets defect. Source: author.

\footnotetext{
*Corresponding author: plachy@mail.vstecb.cz
} 
One of the possible causes of this failure in multilayer systems is the failure to observe the technological discipline. The top bitumen sheet is not full-scale smelting to the base of bitumen sheets. The shrinkage effect is primarily borne by the bitumen sheet with a polyester carrier liner which is not reinforced with glass fibers. The bitumen sheet is preloaded during production, which gradually releases each additional thermal stress. This thermal stress is applied by full-scale smelting application and after exposure by exposure to sunlight. The aim of this paper is to show how great is the effect on the loosening of the pre-stressing in the carrier layer with full-scale smelting during the realization of the waterproofing layer of bitumen sheets reinforced with glass fibers.

The issue of volume changes of bitumen sheets has been dealt with in great detail [2], which in its results, among other things, indicates that the most suitable for flat roofs are bitumen sheets with a composite carrier of polyester fiber reinforced with glass fibers. It also highlights the effect of the volume bulk. Another author [3] notes the force effects that are introduced into the carrier during the production of bitumen sheets.

Although the authors [2], [3] agree that carrier liners made from polyester reinforced with glass fibers are the most suitable for bitumen sheets, it is now possible to encounter bitumen sheets that contain the carrier liner only from polyester fibers. The reason for using these carrier lines are primarily economic reasons.

It is clear from previous research [4] that full-scale smelting of bitumen sheets with a polyester carrier liner has a decisive influence on the dimensional stability of bitumen sheets. Therefore, it was hypothesized that this will not apply for bitumen sheets with a polyester carrier liner reinforced with glass fibers. Full-scale smelting bitumen sheets release very low pre-stressing that is in bitumen sheets. This pre-stressing is reflected by shrinking the sample. The shrink value after heating will be minimally $90 \%$ of total shrinkage. The authors assume that only bitumen sheets with polyester carrier liner reinforced with glass fibers will make very small volume changes of up to $0.3 \%$.

\section{Material and methods of testing}

\subsection{Materials}

For the tests, two bitumen sheets were selected with a multilayer carrier of polyester reinforced with glass fibers. Both samples are designed as a top layer of a multilayer system. The application method is the melting in the total area, refer to Figure 2 and Table 1.

Table 1. Bitumen sheets - Dimensions and characteristics. Signification: E - the mass modified by elastomers, PY + ST - polyester reinforced by glass fibers. Source: author.

\begin{tabular}{|c|c|c|c|c|c|}
\hline $\begin{array}{c}\text { Characteristics } \\
\text { of the test } \\
\text { sample / number } \\
\text { of test sample }\end{array}$ & \multirow{2}{*}{$\begin{array}{c}\text { Bitumen } \\
\text { coating } \\
\text { matter }\end{array}$} & $\begin{array}{c}\text { Nominal } \\
\text { thickness } \\
{[\mathbf{m m}]}\end{array}$ & Material & $\begin{array}{c}\text { Type of } \\
\text { reinforcement }\end{array}$ & $\begin{array}{c}\text { Area } \\
\text { weight } \\
{\left[\mathbf{g} / \mathbf{m}^{2}\right]}\end{array}$ \\
\hline JM 059160 & $\mathrm{E}$ & 4.2 & PY+ ST & thread reinforced & 160 \\
\hline JM 059180 & $\mathrm{E}$ & 4.2 & PY+ ST & thread reinforced & 180 \\
\hline
\end{tabular}




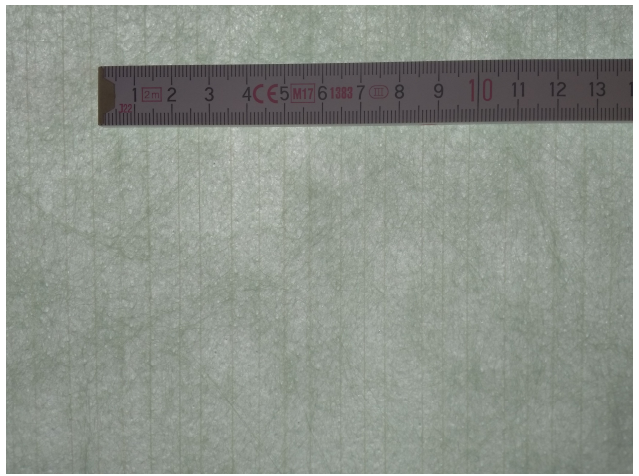

A

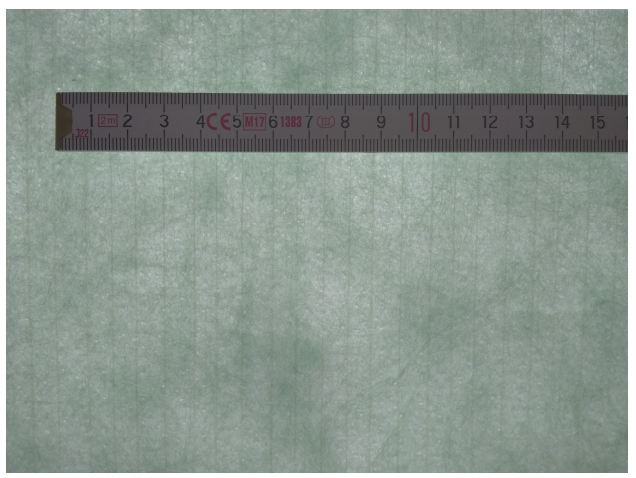

B

Fig. 2. Carrier liner of bitumen sheets. Signification: A - JM 059160, B - JM 059180. Source: author.

\subsection{Methods of testing}

The test samples were made according to ČSN EN 1107-1 [5] for the mechanical method of the sliding scale. Based on experience [4], further measurement intervals of 6, 12, 48, 72 and 96 hours were determined for measurement. The steady state in terms of dimensional stability was to occur in 96 hours

The procedure for the preparation of samples and test specimens was the same as in previous research [4]. For each sample, nine test samples were always prepared in the longitudinal direction of the production of bitumen sheets. An increase in the number of test specimens from five to nine, which is prescribed in [4], was due to the better statistical evaluation. Samples simulating full-scale smelting were labeled as JM059160 n80, JM059180 $\mathrm{n} 80$. The simulation of full-scale smelting was achieved by heating the bitumen sheets with a propane-butane burner after the measuring points were prepared from a distance of $100 \mathrm{~mm}$ (about 5 seconds during the melting of the separation film). The measuring points were protected against flame by the aluminium foil.

\subsection{Evalution}

In total, four samples were processed for the evaluation, for each sample of nine test specimens. The resulting value is given as the mean value of the valid measurements, including the standard deviation, which tells how the values of the statistical set differ from the mean value. It was evaluated:

- the pecentage of the initial prestressing expressed in bitumen sheets for samples JM059160 n80, JM059180 n80, released after exposure to flame,

- whether the samples comply with the requirements of the ČSN 730605-1 standard [6], namely $0.5 \%$ shrinkage in 24 hours exposure at $80{ }^{\circ} \mathrm{C}$. The evaluation shall be carried out including samples which have been exposed to the flame (JM059160 n80, JM059180 n80). 


\section{Results}

The measurement results are shown in the graph in Figure 3.

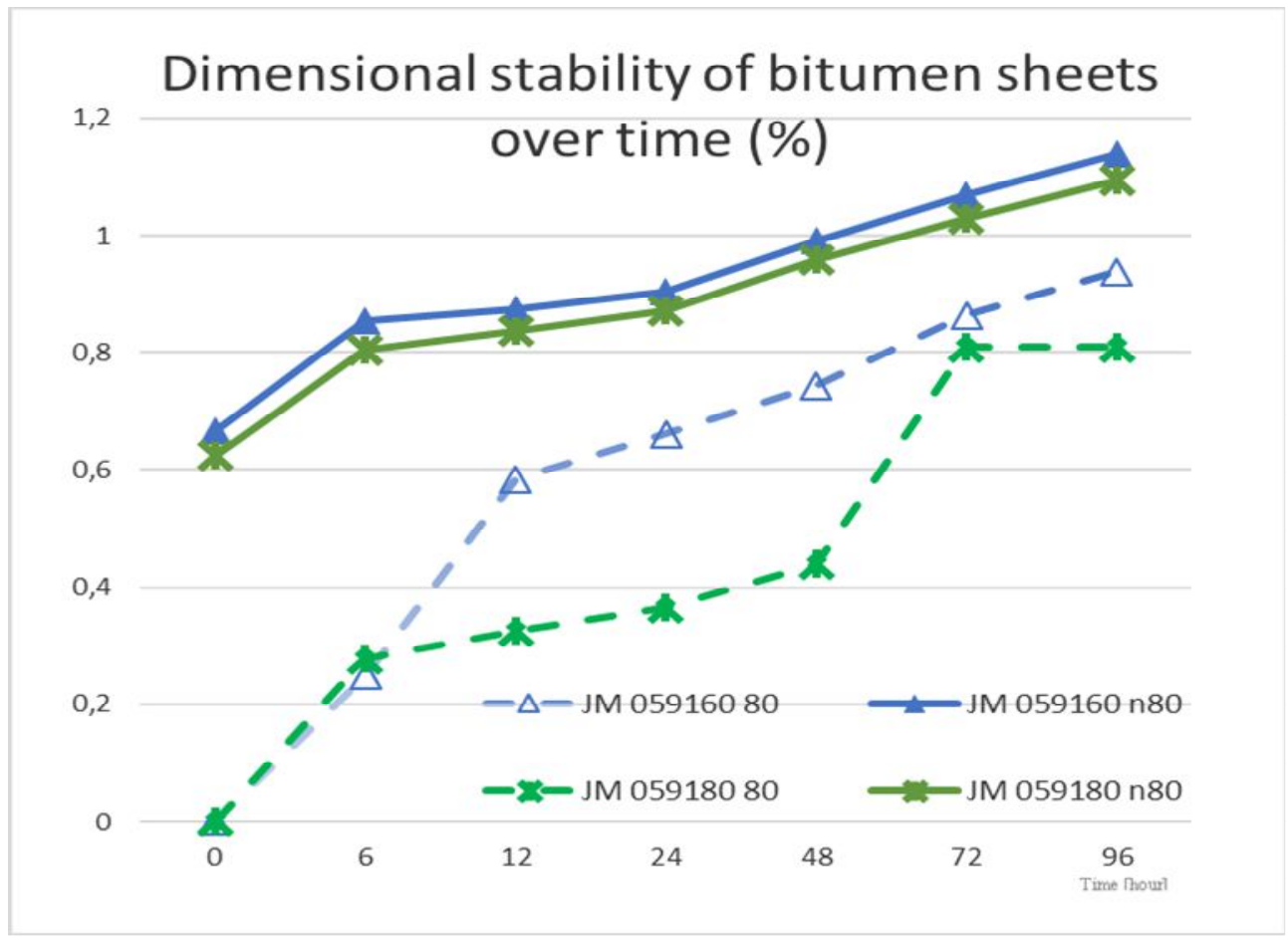

Fig. 3. Dimensional stability of bitumen sheets over time. Source: author.

\section{Discussion}

The hypothesis that more than $90 \%$ of shrinkage from the overall shrinkage after the flame exposure was not confirmed. For sample JM059160 n80, 58.6\% of overall shrinkage was achieved, for sample JM059180 n80, was achieved 57.1\% of total shrinkage, overall, less than the for samples which are supported by polyester liners only [4]. For both samples, a maximum shrinkage was achieved in 96 hours. The initial shrinkage in both samples moved from $0.63 \%$ to $0.67 \%$. Bitumen sheets have behaved in the same way as in previous research [4]. Samples had a higher shrinkage after flame exposure than expected (up to $0.3 \%$, see chapter 2.3 ). Thus, a pre-stressing has been introduced into bitumen sheets with the composite carrier liner, the release of which was a shrinkage that did not meet the requirements of the standard [6].

From the point of view of comparison of the results with the requirements of ČSN 730605-1 [6], the results showed different conclusions. The sample JM059180 80 met standard requirements of $0.5 \%$ in 24 hour exposure at $80{ }^{\circ} \mathrm{C}$ fulfilled when it reached the shrinkage of $0.37 \%$. The sample JM059180 80 did not meet the requirements of the standard when it reached the shrinkage of $0.66 \%$. The result can be justified by the higher basis weight of the polyester in the carrier liner and the higher resistance to shrinkage. For samples that were, after exposure to flame, shrinkage was from $0.24 \%$ to $0.25 \%$, see Figure 4. 
Again, it can be stated that the exposure of samples at $80{ }^{\circ} \mathrm{C}$ during 24 hours does not remove most of the pre-stressing that is introduced into bitumen sheets during the manufacture, even though the polyester carrier is reinforced with a glass fibers. Due to the course of the shrinkage, it is possible to assume that the shrinkage would continue. It is interesting to note that the shrinking of samples is as if their inserts were not reinforced with glass fibers. This result can be justified by the temperature at which the production of bitumen sheets takes place. This temperature is up to $180{ }^{\circ} \mathrm{C}$, conversely, the flame temperature at melting, although acting in the short term, is $1100 \pm 100{ }^{\circ} \mathrm{C}$.

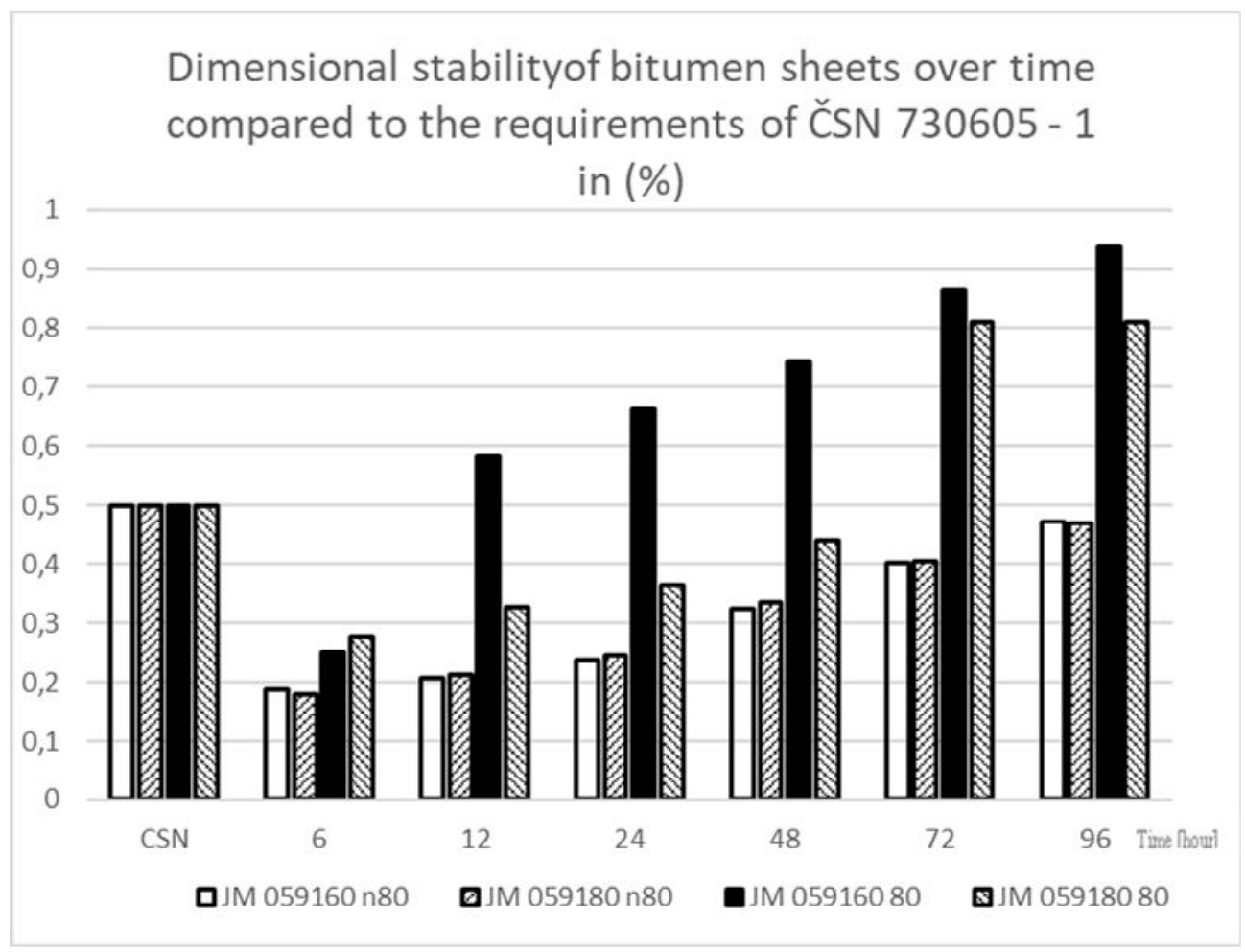

Fig. 4. The effect of the time exposure on the dimensional stability of bitumen sheets over the time. Source: author.

\section{Conclusion}

It can be stated that in the case of bitumen sheets intended for the top layers in a multilayer system with a polyester support which is reinforced with glass fibers and are intended for full-scale smelting application, the full melting is not decisive for releasing the prestressing that is introduced in the production of bitumen sheets.

The test results showed that the higher bulk density of the support liner meets the requirements of the standard even without flame exposure. However, overall sample shrinkage after 96 hours is no longer met by the requirements of the standard [6], [7]. For samples after flame exposure, the shrinkage value was just below the required value $0.5 \%$.

In the next phase of the research, an attention will be focused on the time interval of measurement and bitumen sheets with composite carrier liners made of the polyester reinforced by glass fibers. 


\section{References}

1. T. Petricek, P. Kacalek, MATEC Web of Conferences, 146, 02017 (2017)

2. P. Malych, Volume changes of bitumen coatings. Volume changes of bitumen membranes. (University of Technology in Bratislava, Faculty of civil engineering, Bratislava, 2001)

3. J. Plachý, Volume changes of bitumen sheets. (Roof Symposium, Bratislava, 2010)

4. J. Plachy, J. Vysoka, R. Vejmelka. MATEC Web of Conferences, 146, 02016 (2017)

5. ČSN EN 1107-1. Flexible sheets for waterproofing - Part 1: Bitumen sheets for roof waterproofing - Bitumen sheets for roof waterproofing - Determination of dimensional stability (2000)

6. ČSN 730605-1. Waterproofing of construction works-Flexible sheets for waterproofing - Requirements for use of bitumen sheets

7. ČSN EN 13707. Flexible sheets for waterproofing - Reinforced bitumen sheets for roof waterproofing - Definitions and characteristics (2014) 